\title{
Traduzindo metáforas: uma análise comparativa em tirinhas do Garfield
}

\author{
Mariana de Andrade Doninelli ${ }^{\top}$
}

Resumo: Através da análise de dez tirinhas do Garfield, esse artigo tem como objetivo discutir a tradução da metáfora, com base nas teorias de van den Broeck (1981) e de Lakoff e Johnson (2002). De acordo com a teoria descritivista do primeiro autor, há três procedimentos de tradução para metáforas. Para Lakoff e Johnson, a metáfora não é um simples ornamento linguístico. Eles afirmam que nós não só falamos metaforicamente, como vivemos, pensando e agindo, por metáforas. Entendendo o papel central da metáfora em uma cultura e sabendo que traduzir metáforas significa "traduzir cultura", realizar uma pesquisa sobre tradução de metáforas não é só importante, mas vital para os estudos da tradução.

Palavras-chave: Metáfora; Tradução; Tirinhas do Garfield.

Abstract: Through the analysis of ten Garfield comic strips, this paper aims at discussing metaphor
translation based on van den Broeck's (1981) and Lakoff and Johnson's (2002) theories. According to
the descriptive theory of the first author, there are three possible procedures to translate metaphors.
For Lakoff and Johnson, metaphor is not a simple language ornament. They claim we not only
speak metaphorically. We live, thinking and acting, by metaphors. Understanding the central role
metaphor plays in a culture and knowing that translating metaphor also means "translating culture",
doing a research about metaphor translation is not only important, but vital to translation studies. Keywords: Metaphor; Translation; Garfield comic strips.

1 Aluna do Mestrado Profissional em Educação da Universidade Estadual do Rio Grande do Sul/UERGS; Especialista em Traduação de Inglês pela Universidade Estácio de Sá/UNESA (2015); Licenciada em Letras-Inglês pela Universidade do Vale do Rio dos Sinos/UNISINOS (2002). 


\section{Introdução}

$\mathrm{Na}$ atividade da tradução são muitos os desafios encontrados, um deles se refere à tradução de metáforas. Os teóricos "Lakoff e Johnson têm tratado as metáforas linguísticas como expressões de metáforas conceptuais preexistentes na mente do falante" (ZANOTTO et al., 2002, p. 31). Esses autores entendem que a metáfora está ligada a todo um sistema conceptual de uma cultura, o que faz com que possa haver algum grau de dificuldade na tradução de metáforas de uma língua, referente a uma comunidade com sua cultura específica, para a língua de uma outra população, com outra cultura.

Analisando a teoria desenvolvida por van den Broeck (1981 apud KOGLIN; SOUZA, 2008), é possível constatar que, diante das metáforas, o tradutor pode adotar três possibilidades de tradução: stricto sensu (tradução que transfere, literalmente, o tópico e o veículo presentes no texto fonte para o texto alvo); substituição (substituição da metáfora da língua-fonte para outra similar na língua-alvo) ou paráfrase (tradução da metáfora do texto fonte por um enunciado não metafórico no texto alvo).

O corpus estudado compreende dez tirinhas do Garfield, publicadas em inglês e português. Considerando esse corpus e diante das três possibilidades apresentadas por van den Broeck (1981), percebe-se que, ao analisar cada caso, o tradutor pondera sobre a possibilidade de optar entre uma tradução literal, por substituir a metáfora por uma equivalente ou, ainda, pela paráfrase. O estudo a que se propõe esse artigo objetiva analisar as escolhas tradutórias apresentadas nas tirinhas selecionadas, observando quais foram adotadas e se elas se mostraram funcionais dentro do contexto (serviram ao seu objetivo, comunicando a ideia original com clareza), bem como apontar qual ou quais são as escolhas que aparecem com maior frequência.

O tema central escolhido (tradução de metáforas) se justifica por sua relevância linguístico-cultural, pois, segundo Lakoff e Johnson (2002, p. 43), “a metáfora desempenha um papel essencial na linguagem cotidiana e no pensamento" e "nosso sistema conceptual ordinário, em termos do qual não só pensamos mas também agimos, é fundamentalmente metafórico por natureza" (LAKOFF; JOHNSON, 2002, p. 45). Sendo assim, o estudo sobre a metáfora constitui-se, por si só, bastante relevante e o estudo da tradução da metáfora ainda mais, tendo em vista que o sistema conceptual citado pelos autores está diretamente ligado à cultura. Assim, ao tentar "transferir" conceitos e expressões metafóricas de uma língua para outra é necessário considerar, antes de tudo, as culturas envolvidas, 
assegurando que a tradução da metáfora seja funcional, visto que os sistemas conceptuais dos falantes das línguas envolvidas podem divergir.

A fim de contribuir no campo dos estudos acerca da tradução, essa pesquisa se propõe a explorar as possibilidades de "transferência" da metáfora de uma língua e cultura para outra, a saber: do inglês americano para o português brasileiro. Para tanto, foi selecionado um corpus que, como já mencionado, compreende dez tirinhas do Garfield, retiradas de livros publicados nos Estados Unidos e suas correspondentes versões publicadas no Brasil. Através de uma análise comparativa entre as tirinhas em inglês e português, determina-se qual a escolha adotada pelo tradutor e a funcionalidade de cada tradução.

\section{PRESSUPOSTOS TEÓRICOS}

\subsection{Teoria da Metáfora Conceptual}

Para Lakoff e Johnson (2002), embora por muito tempo a metáfora tenha sido concebida apenas como um recurso da imaginação, um enfeite poético ou retórico, na realidade ela não só permeia nosso discurso, estando presente na linguagem, como também se encontra em nosso pensamento e em nossas ações. Assim, segundo os autores, "O modo como pensamos, o que experienciamos e o que fazemos todos os dias são uma questão de metáfora" (LAKOFF; JOHNSON, 2002, p. 46).

Os mesmos autores, que escreveram a obra Metáforas da Vida Cotidiana (2002), explicam que a metáfora conceptual é cultural. No livro, eles dão como exemplo a seguinte metáfora: DISCUSSÃO É GUERRA² (LAKOFF; JOHNSON, 2002, p. 46-48). Essa é uma metáfora conceptual presente em nossa cultura. Concebemos discussão como guerra e por isso dizemos: "Ele derrubou todos os meus argumentos; Destrui sua argumentação; Suas críticas foram direto ao alvo" (LAKOFF; JOHNSON, 2002, p. 46, grifos dos autores). Se, em alguma outra cultura, discussão não fosse concebida como guerra em seu sistema conceptual ordinário, mas sim como uma dança, então as expressões metafóricas utilizadas nessa outra cultura não seriam aceitas como na nossa. Dessa forma, dizer que "Suas críticas foram direto ao alvo" não faria sentido, pois

2 Todas as metáforas conceptuais serão destacadas em caixa alta ao longo do texto, seguindo o padrão apresentado por Lakoff e Johnson na obra Metáforas da Vida Cotidiana (2002). 
a metáfora conceptual DISCUSSÃO É GUERRA seria inexistente nesse contexto, havendo, assim um outro modo para falar sobre discussão que estivesse de acordo com a metáfora conceptual da cultura em questão (DISCUSSÃO É DANÇA). Nessa segunda cultura, as pessoas pensariam diferentemente acerca de discussão, agiriam de outras formas frente às discussões, logo teriam outras experiências e uma outra linguagem em relação à discussão. Assim, a tradução de metáforas deve levar em consideração o sistema conceptual de cada cultura para a qual se deseja traduzir.

A respeito da teoria de Lakoff e Johnson, Farias (2006, p. 22) explica que a metáfora conceptual é um mapeamento entre domínios, em que "um domínio A (domínio alvo) é compreendido através de um domínio B (domínio fonte)." Assim, na metáfora conceptual AMOR É UMA VIAGEM, o conceito de amor seria compreendido por meio do conceito viagem. Em outras palavras:

[...] a metáfora é um conceito estruturado a partir de outro, é formada por um conceito de origem, de onde parte a produção de sentido, e um conceito alvo, o qual recorre ao significado anterior [...] a metáfora, no sistema conceptual, é entendida como uma projeção [...] entre um domínio fonte, que serve como ponto de referência e onde se buscam conceitos e terminologia, e um domínio alvo, aquele que é explorado e expresso com os elementos fornecidos pelo primeiro. (ALDRIGUE, 2007, p. 30)

Segundo Aldrigue (2007, p. 30), "é importante salientarmos que para um domínio alvo podem ser utilizados vários domínios fontes". Como exemplo, a autora cita o domínio alvo amor, que pode ter como domínios fontes insanidade/ doença, fogo e viagem. Dessa forma, tentamos compreender o amor (domínio alvo) através de diferentes domínios fontes (insanidade/doença, fogo, viagem), o que faz com que se originem expressões como: "Nosso relacionamento é uma loucura sem fim [...] O nosso relacionamento é quente [...] Nós devemos seguir caminhos diferentes" (ALDRIGUE, 2007, p. 31, grifos da autora). A autora salienta que o contrário também pode acontecer, ou seja, "um domínio fonte pode ser utilizado para vários domínios alvos" (p. 31). Como exemplo, Aldrigue cita as metáforas conceptuais DISCUSSÃO É GUERRA e AMOR É GUERRA, sendo que através delas podemos perceber que um mesmo domínio fonte (guerra) é utilizado para domínios alvos diferentes (discussão e amor). Assim, tentamos compreender o amor e a discussão em termos de guerra, originando expressões como: "Seus argumentos não vão me vencer, Ela tentou lutar por ele, mas acabou perdendo a luta" (ALDRIGUE, 2007, p. 31, grifos da autora). 
Um apontamento importante é o de que não podemos confundir metáfora conceptual com expressão metafórica. Se observarmos todos os exemplos citados anteriormente, veremos que as expressões metafóricas provêm das metáforas conceptuais. Assim, através da metáfora conceptual AMOR É FOGO, por exemplo, originam-se expressões metafóricas, como "Quando ele me beija uma chama se acende entre nós" (ALDRIGUE, 2007, p. 31, grifos da autora). A esse respeito, Farias (2006, p. 23) diz que: "por ser uma figura de pensamento, a metáfora conceptual dá origem, ou melhor, 'licencia' expressões metafóricas na linguagem" e que "essas podem ser vistas como evidências ou marcas linguísticas de metáforas conceptuais que as subjazem." Em outras palavras, "as metáforas conceptuais [...] 'motivam' as expressões metafóricas. Sem [...] [essa] motivação, as expressões metafóricas não teriam sentido imediato aparente" (SARDINHA, 2007, p. 33).

São inúmeros os exemplos de metáforas conceptuais e de expressões metafóricas provenientes das mesmas, citadas por Lakoff e Johnson (2002), na obra Metáforas da vida cotidiana. São alguns exemplos:

a) Da metáfora conceptual AMOR É UMA VIAGEM originam-se expressões metafóricas como as destacadas a seguir: "Estamos numa encruzilhada; Não podemos voltar atrás agora; Esta relação é um beco sem saída" (LAKOFF; JOHNSON, 2002, p. 104, grifos dos autores).

b) A metáfora conceptual TEORIAS (E ARGUMENTOS) SÃO CONSTRUÇÕES dá origem às seguintes expressões metafóricas: "Esse é o alicerce de sua teoria?; A teoria precisa de mais sustentação; $\mathrm{O}$ argumento é frágil" (LAKOFF; JOHNSON, 2002, p. 107, grifos dos autores).

c) São expressões provenientes da metáfora conceptual IDEIAS SÃO ALIMENTOS: "Simplesmente não consigo engolir essa afirmação; Há muitos fatos aqui para que eu possa digeri-los de uma só vez" (LAKOFF; JOHNSON, 2002, p. 108, grifos dos autores).

Nas palavras de Sardinha (2007, p. 31), a expressão metafórica é a “expressão linguística que é uma manifestação de uma metáfora conceptual.” Segundo o autor, a metáfora "é uma representação mental. Ela é cognitiva (existe na mente e atua no pensamento). Sendo assim, é abstrata. Porém, embora abstrata, sabemos que ela existe, pois toma forma na fala e na escrita por meio das expressões metafóricas" (SARDINHA, 2007, p. 32).

Sardinha (2007) faz outros apontamentos importantes sobre a teoria proposta por Lakoff e Johnson, dizendo que: 
O acesso às metáforas conceptuais é automático. Normalmente não precisamos de esforço para entender uma expressão metafórica, pois ela automaticamente aciona a metáfora conceptual correspondente na nossa mente. Do mesmo modo, não precisamos de esforço para produzir (falar ou escrever) as expressões metafóricas, pois as metáforas conceptuais gerariam as expressões metafóricas correspondentes. (SARDINHA, 2007, p. 33)

O autor segue, afirmando:

As metáforas conceptuais são culturais. Elas refletem a ideologia e o modo de ver o mundo de um grupo de pessoas, construídos em determinada cultura. Em outras palavras, elas não dependem da vontade do indivíduo. Não podemos normalmente, criar uma metáfora conceptual; se tentarmos, muito provavelmente ela não funcionará como uma verdadeira metáfora conceptual, pois não será compartilhada em sociedade. (SARDINHA, 2007, p. 33)

Como podemos observar, a metáfora conceptual está presente em nossa mente e o acesso a ela se dá de forma natural, de acordo com cada cultura. Assim, se alguém disser "Essa gripe me derrubou" em nossa cultura, todos irão entender que a gripe deixou o falante abatido, sentindo-se mal, sem energia, visto que o ouvinte acessaria sem esforço as metáforas conceptuais SAÚDE E VIDA SÃO PARA CIMA/ DOENÇA E MORTE SÃO PARA BAIXO. Ninguém iria relacionar essa fala a uma queda no sentido literal da palavra. Em outra cultura, em que não houvesse tais metáforas conceptuais, tal fala poderia causar incompreensão ou estranhamento.

Em relação à classificação, segundo Lakoff e Johnson (2002), as metáforas conceptuais podem ser estruturais, orientacionais ou ontológicas.

As metáforas estruturais são aquelas em que "um conceito é estruturado metaforicamente em termos de outro" (LAKOFF; JOHNSON, 2002, p. 59), como em DISCUSSÃO É GUERRA, em que o conceito de discussão é estruturado em termos de guerra.

As metáforas orientacionais são assim chamadas por estarem relacionadas à orientação espacial. Assim, são metáforas desse tipo: FELIZ É PARA CIMA/ TRISTE É PARA BAIXO; SAÚDE E VIDA SÃO PARA CIMA/ DOENÇA E MORTE SÃO PARA BAIXO; BOM É PARA CIMA/ MAU É PARA BAIXO; gerando expressões metafóricas como: Tenho me sentido muito para baixo; Hoje estou me sentido radiante, estou nas alturas! etc. 
As metáforas ontológicas, por sua vez, "nascem de nossas experiências com objetos físicos e nos permitem compreender coisas abstratas como entidades e substâncias em termos de coisas concretas e/ ou convencionais" (KOGLIN; OLIVEIRA, 2008, p. 3). Nas palavras de Lakoff e Johnson (2002, p. 76), "as nossas experiências com objetos físicos (especialmente com nossos corpos) fornecem a base para uma variedade extremamente ampla de metáforas ontológicas, isto é, formas de se conceber eventos, atividades, emoções, ideias etc. como entidades e substâncias." Esses autores apontam a metáfora MENTE É UMA ENTIDADE como uma metáfora ontológica, que faz com que a mente possa ser entendida, por exemplo, em termos de máquina ou de objeto quebradiço, dando origem a expressões metafóricas, tais como: "A minha mente simplesmente não está funcionando hoje [...] Estou um pouco enferrujado hoje [...] A experiência o despedaçon [...] A sua mente pifou (LAKOFF; JOHNSON, 2002, p. 79, grifos dos autores).

Lakoff e Johnson (2002, p. 87) dizem que: "talvez as metáforas ontológicas mais óbvias sejam aquelas nas quais os objetos físicos são concebidos como pessoas." A esse caso específico de metáfora ontológica, os autores dão o nome de personificação. É importante salientar que a personificação (atribuição de características humanas àquilo que não é humano) não se dá somente em relação a objetos, mas também a uma gama de outras coisas e "isso nos permite compreender uma grande variedade de experiências concernentes a entidades não-humanas em termos de motivações, características e atividades humanas" (LAKOFF; JOHNSON, 2002, p. 87). Algumas expressões metafóricas provenientes de metáforas ontológicas de personificação são "A vida me trapaceou [...] A inflação está devorando nossos lucros [...] O câncer finalmente o pegou" (LAKOFF; JOHNSON, 2002, p. 87 , grifos dos autores).

\subsection{Tradução de metáforas}

Em relação à tradução de metáforas, Koglin (2008, p. 31) diz:

É, talvez, por intermédio dos estudos descritivos da tradução de metáforas que se torna possível a busca de alternativas mais adequadas por meio da observação e da investigação de decisões tradutórias bem sucedidas. Dentre os autores que apresentam estratégias para traduzir metáforas nesta abordagem, [...] [está] van den Broeck [...]

Dessa fala, podemos inferir que van den Broeck não apresenta uma teoria prescritivista, não define como se deve traduzir metáforas, mas “desenvolveu uma 
teoria descritivista, que se propõe explicar e descrever soluções identificadas" (KOGLIN; SOUZA, 2008, p. 482). Van den Broeck (1981) apresenta três possibilidades tradutórias para as metáforas, abordadas por Koglin e Souza (2008). As autoras explicam que uma dessas possibilidades é a:

Tradução stricto sensu: transferir o tópico e o veículo do texto fonte para o texto alvo. Exemplo: Em I am feeling up today é possível fazer a tradução literal por Estou me sentindo para cima hoje, sem afetar a compreensão, supondo que, em ambas as línguas, haja o mesmo valor metafórico. (KOGLIN; SOUZA, 2008 , p. 482, grifos das autoras)

Segundo Sardinha (2007), os termos tópico e veículo, os quais são usados até os dias de hoje na descrição da metáfora, foram criados pelo estudioso I. A. Richards. O autor diz que, segundo esse teórico, tópico seria a parte não metafórica do enunciado, enquanto o veículo corresponderia justamente à parte metafórica. Koglin (2008) complementa, afirmando, em relação ao tópico e ao veículo, que "O primeiro [tópico] se refere àquilo de que falamos, enquanto o segundo [veículo] diz respeito ao termo da afirmativa a partir do qual a analogia é criada, sendo que apenas algumas características do veículo são transferidas ao tópico" (KOGLIN, 2008, p. 42).

A autora explica, ainda, que a estrutura da metáfora é composta por estes dois termos (tópico e veículo) e que:

Quando dizemos, por exemplo, que alguém é uma mala, temos o alguém como tópico e a mala como veículo, a partir do qual apenas algumas características são destacadas e atribuídas ao tópico, nesse caso, o desconforto e o incômodo causado por uma mala. (KOGLIN, 2006, p. 4)

$\mathrm{Na}$ tradução stricto sensu, ambos (tópico e veículo) seriam traduzidos literalmente, de forma que tanto o leitor do texto fonte, quanto o leitor do texto alvo, fossem capazes de compreender o mesmo enunciado, devido à existência de um mesmo valor metafórico entre as duas culturas envolvidas.

Outra possibilidade tradutória citada por Koglin e Souza (2008) com base na teoria de van den Broeck (1981) é:

Substituição: substituir o veículo da língua fonte por um veículo que tenha um teor parecido na língua alvo. Exemplo: Na expressão Paddle your own canoe, a tradução literal seria Reme sua própria canoa. Assim, o leitor da língua portuguesa poderia não entender o seu sentido, que, em nossa cultura 
muito frequentemente é expresso por meio de expressões como Ande com suas próprias pernas, isto é, seja autônomo. (KOGLIN; SOUZA, 2008, p. 482, grifos das autoras)

No exemplo citado acima, o enunciado metafórico da língua-fonte é substituído por outro correspondente na língua-alvo, visto que não há a possibilidade de tradução literal, a qual causaria grande estranhamento por parte do leitor da língua portuguesa. Assim, para os falantes do português brasileiro, faria muito mais sentido dizer Ande com suas próprias pernas, que já é uma expressão consagrada, optando pela estratégia de substituição e, assim, evitando mal-entendidos e priorizando uma melhor comunicação, que esteja de acordo com a cultura local, para a qual se deseja traduzir.

Por vezes, pode ocorrer impossibilidade de tradução literal (stricto sensu) ou o tradutor pode ter dificuldade em encontrar uma expressão metafórica equivalente, realizando uma substituição adequada. Nesses casos, há a possibilidade de optar pela paráfrase. Essa possibilidade, também apresentada por van den Broeck (1981), é assim explicada por Koglin e Souza:

Paráfrase: traduzir a metáfora da língua fonte por uma expressão não metafórica na língua alvo. Exemplo: Para a expressão metafórica couch potato, que é empregada em referência a pessoas que gastam muito tempo sentadas ou deitadas, usualmente assistindo à televisão, não teríamos possibilidade de tradução stricto sensu, uma vez que, em português, batata de sofá seria considerada uma expressão sem sentido. Também não seria tarefa fácil encontrar expressão metafórica que pudesse substituir couch potato, em português. Nesse caso, seria adequado e necessário parafrasear a expressão, de modo a explicar seu sentido, distanciando naturalmente o texto alvo do texto fonte em termos de expressão linguística. (KOGLIN; SOUZA, 2008, p. 482, grifos das autoras)

Devido às diferenças linguísticas e culturais entre os povos, a metáfora pode ser vista como uma dificuldade na tarefa de traduzir. Entretanto, como vimos, há teóricos que nos permitem estudar e compreender não só a metáfora, mas também como se dá a sua tradução, possibilitando a pesquisa que será apresentada.

\section{ANÁLISE DO CORPUS}

Foram selecionados 10 pares de tirinhas do Garfield para análise, visando determinar qual metáfora conceptual "aparece" em cada par de tiras, bem como 
as expressões metafóricas licenciadas pelas mesmas e, ainda, quais foram as alternativas de tradução escolhidas pelos tradutores e aplicadas em cada caso e se as mesmas se mostraram funcionais no contexto de cada tirinha.

Segue, abaixo, a análise das tirinhas selecionadas:

\section{Tirinha 1}
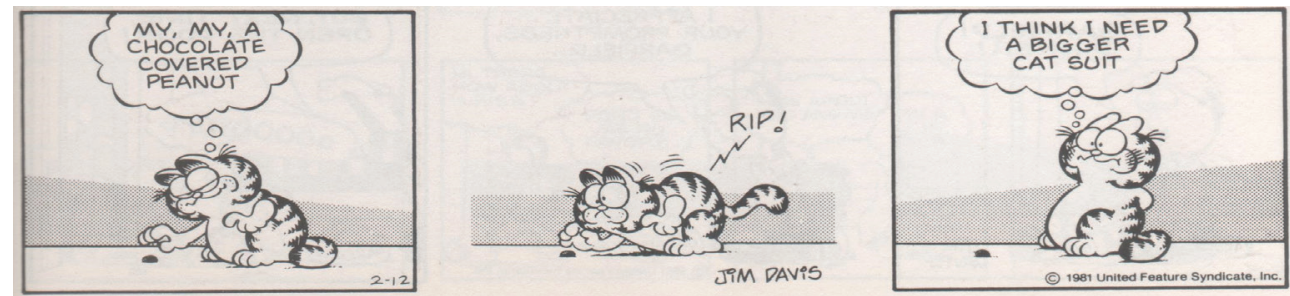

Fonte: DAVIS, Jim. Garfield takes the cake. Nova Iorque: Ballentine Books, 1982, não paginado.
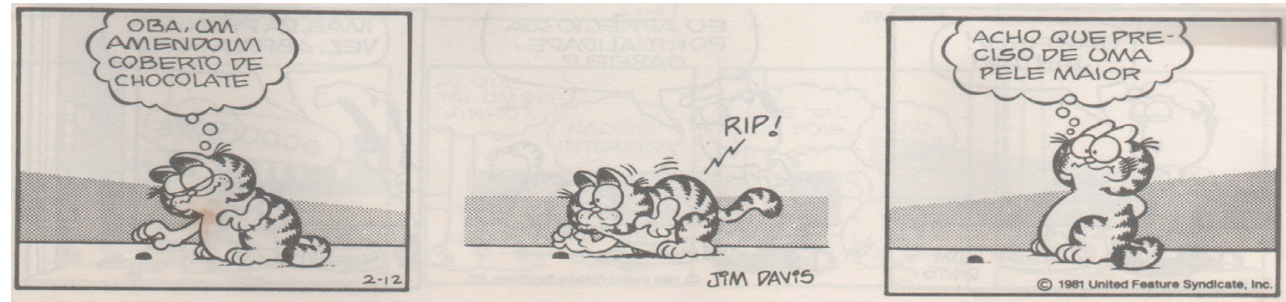

Fonte: DAVIS, Jim. Garfield leva o bolo. São Paulo: Cedibra, 1982, não paginado.

\section{Metáfora conceptual: PELE É UMA ROUPA}

Expressão metafórica licenciada (em destaque): I think I need a bigger cat suit.

Tradução para a língua-alvo: Acho que preciso de uma pele maior.

Alternativa de tradução aplicada: paráfrase

Funcionalidade da tradução: Ao traduzir a expressão metafórica cat suit, o tradutor optou por usar uma palavra sem valor metafórico (pele). O tradutor poderia ter optado pela tradução literal, que compreende a pele do gato como roupa (terno; traje/suit), visto que, em ambas as culturas se verifica a metáfora conceptual PELE É UMA ROUPA. Entretanto, optou por uma paráfrase, fazendo-se entender com o auxílio das imagens que se apresentam nas tirinhas, em que a pele do personagem se "rasga" como uma roupa, devido ao excesso de peso. Assim, a tradução é funcional, embora haja uma certa perda do ponto de vista cômico evidenciado na tirinha original, que aponta a pele como uma roupa pequena demais para o tamanho do gato. 
Tirinha 2
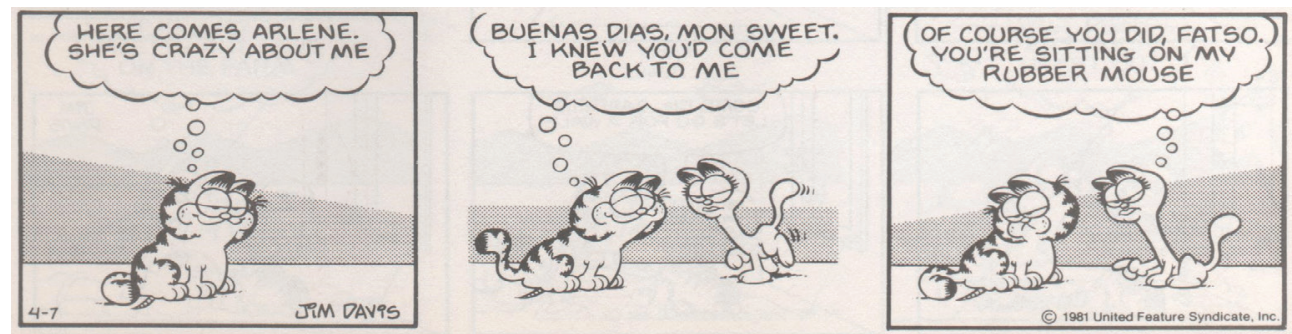

Fonte: DAVIS, Jim. Garfield takes the cake. Nova Iorque: Ballentine Books, 1982, não paginado.
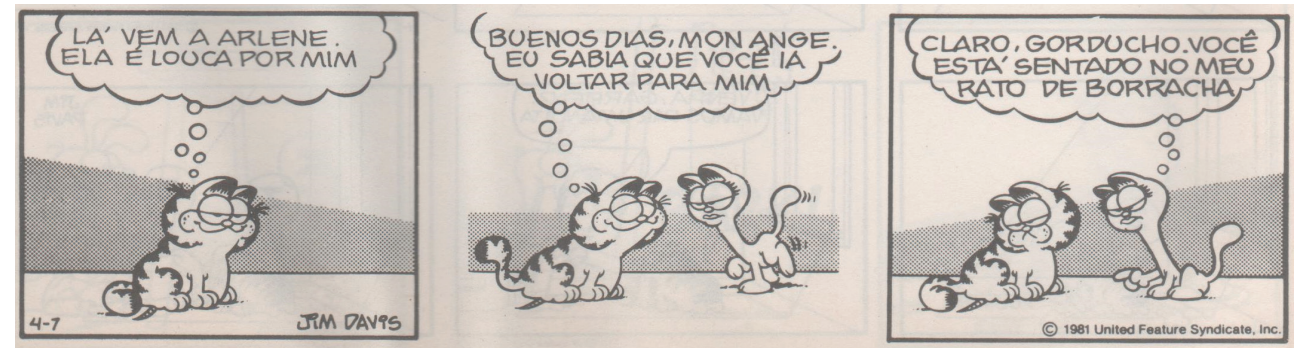

Fonte: DAVIS, Jim. Garfield leva o bolo. São Paulo: Cedibra, 1982, não paginado.

\section{Metáfora conceptual: AMOR É LOUCURA}

Expressão metafórica licenciada (em destaque): She’s craay about me.

Tradução para a língua-alvo: Ela é louca por mim.

Alternativa de tradução aplicada: stricto sensu

Funcionalidade da tradução: A tradução literal é bastante funcional, tendo em vista que em ambas as culturas é possível conceber o amor em termos de loucura, licenciando expressões como ser louco por alguém. 
Tirinha 3
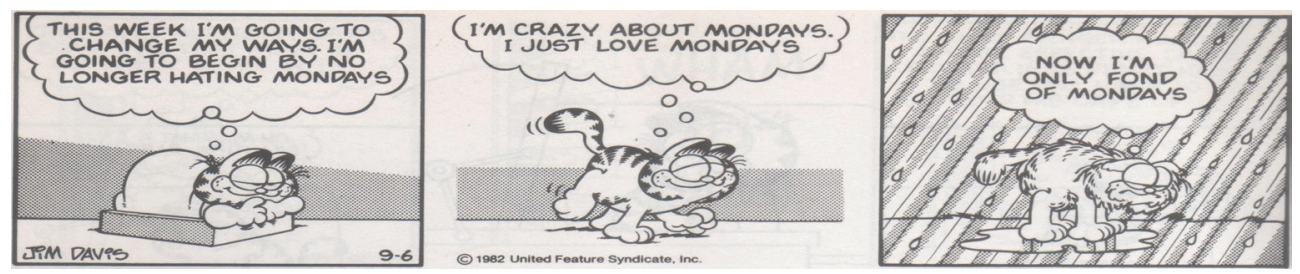

Fonte: DAVIS, Jim. Garfield tips the scales. Nova Iorque: Ballentine Books, 1984, não paginado.
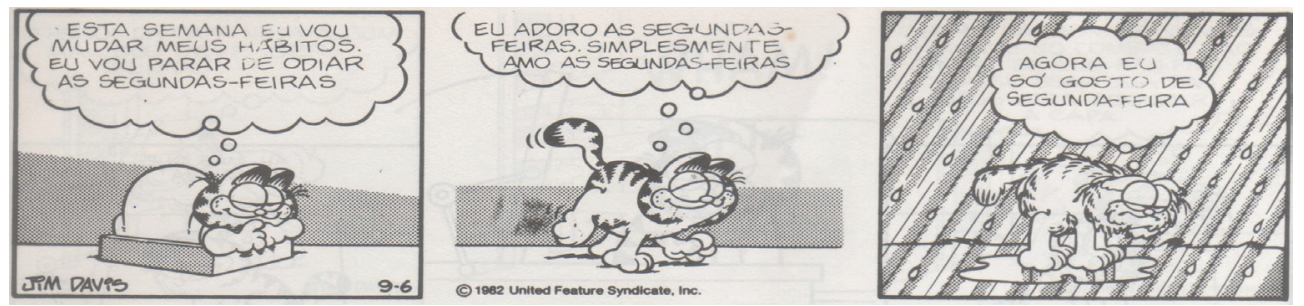

Fonte: DAVIS, Jim. Garfield na balança. São Paulo: Cedibra, 1986, não paginado.

\section{Metáfora conceptual: AMOR É LOUCURA}

Expressão metafórica licenciada (em destaque): I'm crasy about Mondays.

Tradução para a língua-alvo: Eu adoro as segundas-feiras.

Alternativa de tradução aplicada: paráfrase

Funcionalidade da tradução: Como no par de tirinhas anterior, percebe-se, no texto original, a presença da metáfora conceptual AMOR É LOUCURA, que dá origem à expressão metafórica ser louco por algo/alguém. Embora tal expressão exista tanto no inglês americano (crasy about someone/something) quanto no português brasileiro, visto que nas culturas de ambos os povos falantes dessas línguas existe a mesma metáfora conceptual, que concebe amor como loucura, ainda assim o tradutor optou por traduzir "I'm crasy about Mondays" por "Eu adoro as segundas-feiras", escolhendo aplicar a paráfrase em sua tradução.

Quando analisamos as tirinhas, percebemos a funcionalidade da tradução adotada, pois através de ambos os enunciados verificamos a postura do personagem em encarar as segundas-feiras com otimismo. Quem conhece bem as histórias de Garfield sabe que, na verdade, o gato detesta segundas-feiras, acredita que coisas ruins lhe acontecem só por ser esse dia da semana, que é encarado por ele como se fosse um dia de azar. Quando ele diz "I'm crasy about Mondays" ou "Eu adoro as segundas-feiras", mostra sua vontade em transformar o que é, para ele, um dia tradicionalmente de acontecimentos ruins, em um bom dia. Essa postura de encarar o dia de forma positiva e feliz é expressa, sem prejuízo, pela paráfrase empregada pelo tradutor. 


\section{Tirinha 4}
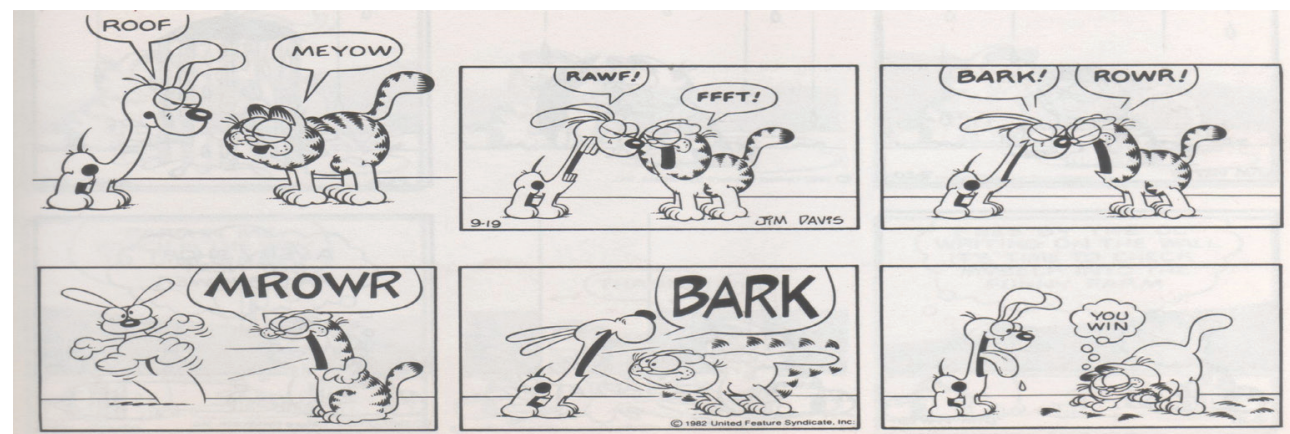

Fonte: DAVIS, Jim. Garfield tips the scales. Nova Iorque: Ballentine Books, 1984, não paginado.
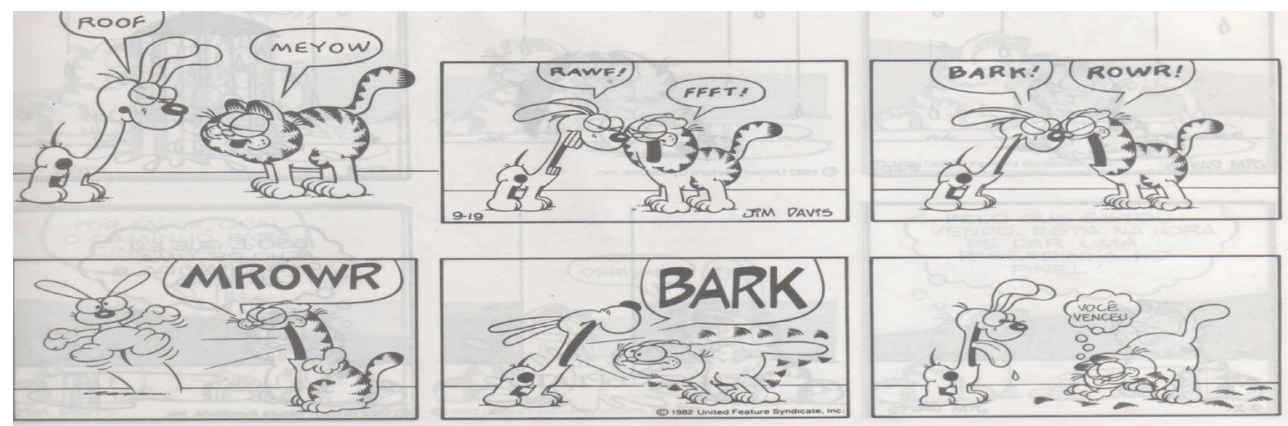

Fonte: DAVIS, Jim. Garfield na balança. São Paulo: Cedibra, 1986, não paginado.

Metáfora conceptual: DISCUSSÃO É GUERRA

Expressão metafórica licenciada (em destaque): You win.

Tradução para a língua-alvo: Você venceu.

Alternativa de tradução aplicada: stricto sensu

Funcionalidade da tradução: A tradução literal mostra-se eficiente, visto que em ambas as culturas se verifica a existência da metáfora conceptual DISCUSSÃO É GUERRA, ou seja, tanto nos Estados Unidos quanto no Brasil se concebe discussão em termos de guerra, o que nos permite dizer, por exemplo, que ganhamos ou perdemos uma discussão. 
Tirinha 5
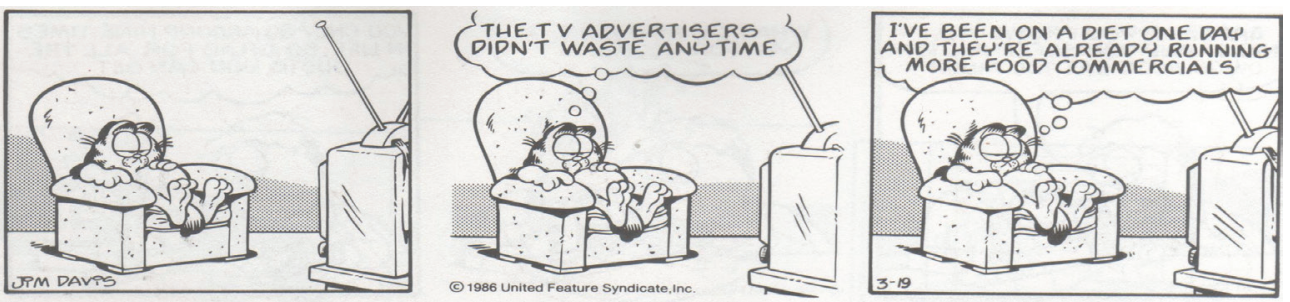

FONTE: DAVIS, Jim. Garfield swallows his pride. Nova Iorque: Ballantine Books, 1987, não paginado.
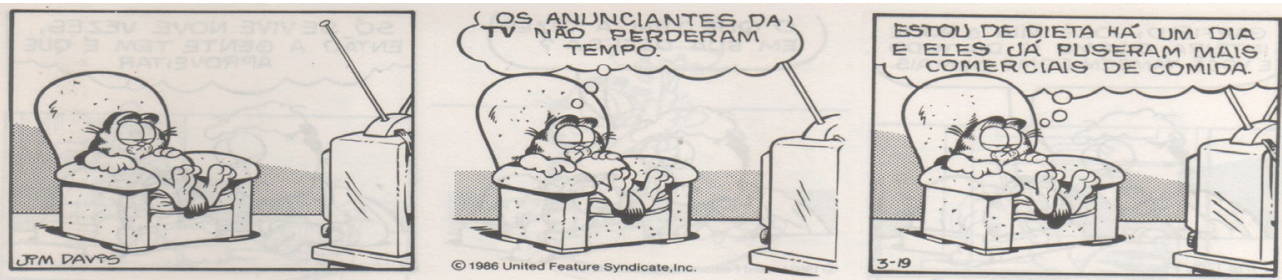

FONTE: DAVIS, Jim. Garfield em ação 13. Rio de Janeiro: Salamandra, 1989, não paginado.

\section{Metáfora conceptual: TEMPO É DINHEIRO}

Expressão metafórica licenciada (em destaque): The TV advertisers didn’t waste any time.

Tradução para a língua-alvo: Os anunciantes da tv não perderam tempo.

Alternativa de tradução aplicada: stricto sensu

Funcionalidade da tradução: Embora não existam palavras que sejam sinônimos perfeitos, que possam substituir uma a outra, com exatidão, em qualquer contexto, a expressão perder tempo parece ter sido uma escolha adequada, visto que carrega a ideia de "desperdício" explicitada na expressão waste time. Por isso, considera-se que, nesse contexto, waste e perder têm significados equivalentes. Assim, a tradução de um termo por outro se apresenta como uma tradução stricto sensu.

Em nossa cultura, assim como na cultura americana, existe a metáfora conceptual TEMPO É DINHEIRO, que nos permite dizer que podemos ganhar tempo, perder/ desperdiçar tempo, gastar ou investir tempo, etc. Segundo Lakoff e Johnson (2002, p. 51): "Pelo fato de que agimos como se o tempo fosse um bem valioso - um recurso limitado, como o dinheiro - nós o concebemos dessa forma" (grifo dos autores). Eles seguem, afirmando: "Logo, compreendemos e experienciamos o tempo como algo que pode ser gasto, desperdiçado, orçado, bem ou mal investido, poupado ou liquidado” (p. 51). Assim, expressões como waste time e perder tempo são metafóricas, pois estamos conceitualizando um termo (tempo) em termos de nossas experiências com outro (dinheiro). 
Não só na cultura americana, como em nossa cultura, também capitalista-ocidental, a metáfora conceptual apresentada é bastante comum, por isso as expressões metafóricas por ela licenciadas são de fácil identificação e compreensão por parte da maioria de nós. Assim, a tradução stricto sensu é bastante funcional, considerando que temos uma mesma metáfora conceptual presente em ambas as culturas, licenciando expressões muito parecidas ou até mesmo idênticas em inglês e português, conforme vários exemplos apresentados no livro Metáforas da vida cotidiana, dos autores Lakoff e Johnson (2002). O grupo GEIM, responsável pela tradução da obra, para deixar mais claro os exemplos, optou por colocar ao lado da tradução para o português, os exemplos originais, escritos em inglês. Alguns desses exemplos nos mostram a semelhança (ou até mesmo a correspondência exata) entre as expressões metafóricas apresentadas em ambas as línguas:

Você está desperdiçando meu tempo. Você está me fazendo perder tempo. (You are wasting my time. $)^{3}$

Como você gasta seu tempo hoje em dia? (How do you spend your time these days?) ${ }^{4}$

Tenho investido muito tempo nela. (I've invested a lot of time in her.) ${ }^{5}$

O seu tempo está se esgotando. (You're running out of time.) ${ }^{6}$

Você deve calcular/administrar bem o seu tempo. (You need to budget your time.) $)^{7}$

3 Lakoff; Johnson, 2002, p. 50, grifos dos autores.

4 Lakoff; Johnson, 2002, p. 50, grifos dos autores.

5 Ibidem.

6 Ibidem.

7 Ibidem. 


\section{Tirinha 6}
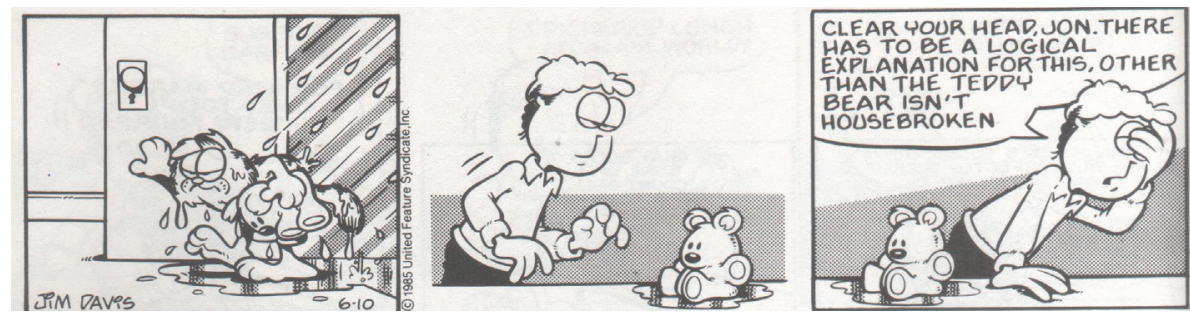

Fonte: DAVIS, Jim. Garfield out to lunch. Nova Iorque: Ballantine Books, 1986, não paginado.
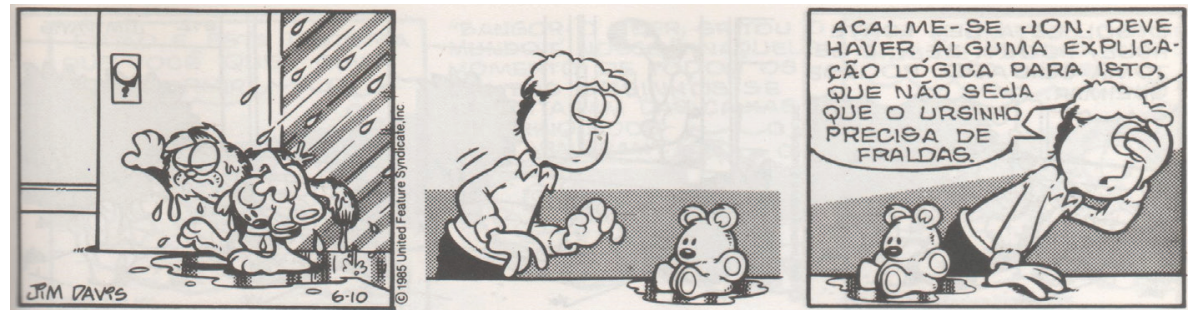

Fonte: DAVIS, Jim. Garfield em ação 10. Rio de Janeiro: Salamandra, 1988, não paginado.

\section{Metáfora conceptual: MENTE É UM RECIPIENTE}

Expressão metafórica licenciada (em destaque): Clear your head, Jon.

Tradução para a língua-alvo: Acalme-se, Jon.

Alternativa de tradução aplicada: paráfrase

Funcionalidade da tradução: A expressão metafórica apresentada na língua-fonte vem da metáfora conceptual MENTE É UM RECIPIENTE, que também está presente em nossa cultura. Apesar disso, a tradução literal não se mostrou possível nesse caso.

A expressão clear your head remete à ideia de esvaziar a mente dos problemas, de removê-los para poder acalmar-se. Nota-se que a tradução literal da expressão metafórica por "Limpe/Esvazie/ Clareie a sua mente/cabeça" não seria possível, uma vez que, em nossa língua, esses enunciados causariam estranheza, não sendo expressões de uso corrente. Assim, não seria a opção mais viável para passar a ideia de "Não se preocupe", sentido apresentado pela expressão metafórica na língua-fonte. Porém, seria possível pensar em possibilidades tradutórias pautadas pela substituição, trocando a expressão metafórica apresentada em inglês por outra semelhante em português, como: "Clareie as ideias" ou "Não esquente a cabeça". Entretanto, o tradutor optou pela paráfrase, traduzindo uma expressão metafórica por outra não metafórica. Assim, o enunciado, que tinha um significado mais abrangente, foi simplificado mas, apesar disso, não parece haver prejuízo para a compreensão do texto. 
Tirinha 7
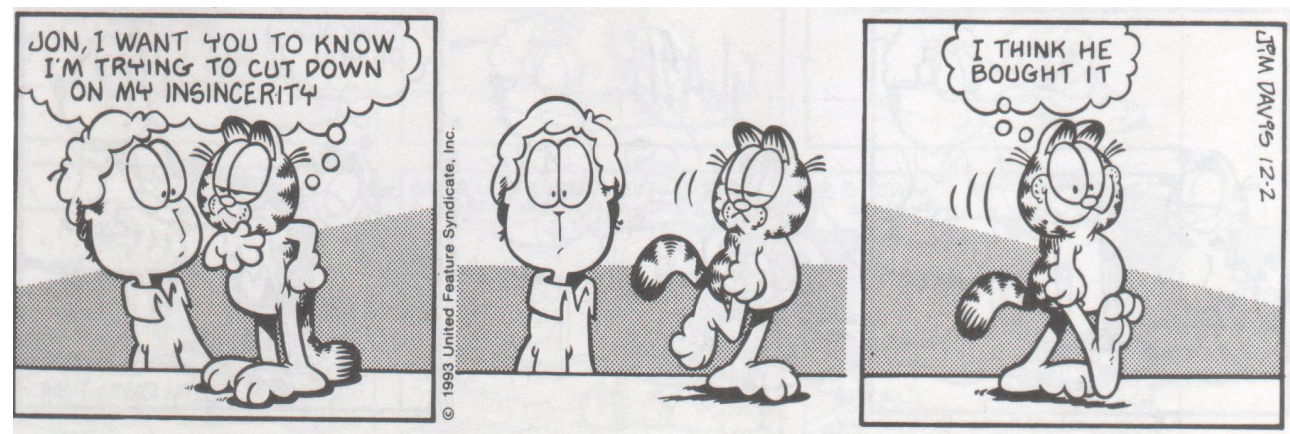

Fonte: DAVIS, Jim. Garfield dishes it out. Nova Iorque: Ballantine Books, 1995, não paginado.
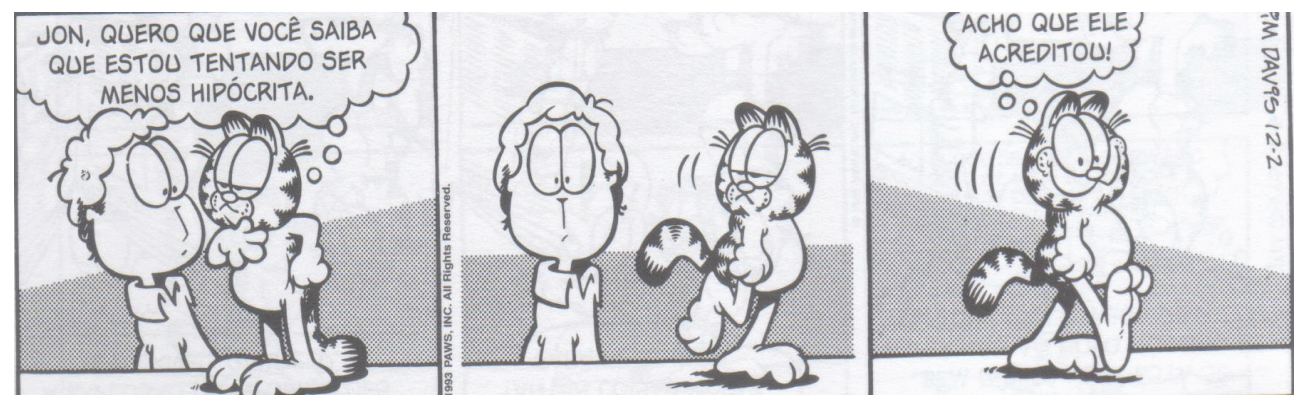

Fonte: DAVIS, Jim. Garfield está de dieta. Porto Alegre: L\&PM, 2013, p. 17.

Na tira acima, há a ocorrência de duas metáforas conceptuais:

a) Metáfora conceptual: QUALIDADE (SINCERIDADE) É UM OBJETO MENSURÁVEL

Expressão metafórica licenciada (em destaque): Jon, I want you to know I'm trying to cut down on my insincerity.

Tradução para a língua-alvo: Jon, quero que você saiba que estou tentando ser menos bipócrita.

Alternativa de tradução aplicada: paráfrase

Funcionalidade da tradução: Qualidades podem ser concebidas como algo de que se tem a posse e que são mensuráveis, calculáveis ou quantificáveis. É o que verificamos nesta tira, a partir de uma metáfora ontológica. Segundo Aldrigue e Espíndola (2011, p. 195), as metáforas ontológicas são aquelas "em que um conceito abstrato é transformado em entidade, objeto ou substância." Lakoff e Johnson (2002, p. 76) explicam que identificar as 
nossas experiências dessa forma nos permite "referir-nos a elas, categorizá-las, agrupá-las e quantificá-las - e, dessa forma, raciocinar sobre elas." Assim, ao conceber o conceito de "sinceridade" como algo que se possui, portanto, como um objeto (my insincerity), torna-se possível mensurá-lo, fazendo com que se possa afirmar que precisa ser "reduzido" (to cut down on my insincerity).

Como vemos na tira original, a metáfora conceptual QUALIDADE É UM OBJETO MENSURÁVEL, circula no inglês americano. Isso também ocorre em relação ao português brasileiro, em que são muitas as expressões metafóricas licenciadas a partir da compreensão de uma qualidade como um objeto pessoal quantificável, o que nos permite dizer, por exemplo: "A honestidade dele é inquestionável. Ele é muito honesto"; "Ele possui uma inteligência notável, grandiosa"; "Ela tem muita paciência"; "O professor tem a paciência curta"; "É preciso ter muita tolerância para lidar com algumas pessoas"; "A minha tolerância esgotou"; Ele tem uma paciência e uma tolerância infinitas."

$\mathrm{Na}$ tira cômica em questão, Garfield afirma estar tentado redu^̨ir a sua insinceridade. A partir da análise desta tira, vemos que qualidades podem ser tratadas como coisas que possuímos e que podem ser mensuradas ou quantificadas. Isso é possível em ambas as línguas: fonte e alvo, mas, embora o tradutor pudesse ter se valido disso e adotado uma tradução stricto sensu, preferiu optar pela paráfrase, modificando o enunciado original, escolhendo como novo enunciado "estou tentando ser menos hipócrita".

O efeito cômico é percebido em ambas as línguas. Na tira em inglês é possível observar que o gato está demonstrando um certo cinismo, ao fingir que está se empenhando em melhorar seu jeito de ser. $\mathrm{Na}$ tradução, a opção adotada faz com que a comicidade da tira seja mantida, uma vez que o tradutor traz um enunciado em que o gato afirma estar tentando ser menos hipócrita, enquanto demonstra justamente o contrário.

b) Metáfora conceptual: IDEIAS SÃO BENS DE CONSUMO

Expressão metafórica licenciada (em destaque): I think he bought it.

Tradução para a língua-alvo: Acho que ele acreditou.

Alternativa de tradução aplicada: paráfrase

Funcionalidade da tradução: Segundo Lakoff e Johnson, a metáfora conceptual IDEIAS SÃO BENS DE CONSUMO licencia expressões metafóricas tais como: "He won't buy that; That idea just won't sell; There is always a market for good ideas" (2002, p. 111, grifos dos autores). Na tirinha apresentada, o tradutor optou pela paráfrase, escolhendo uma frase sem valor metafórico para expressar o humor irônico de Garfield que, deliberadamente, tenta enganar seu dono. A tradução é funcional sob o ponto de vista interlinguístico, visto que os enunciados (I think he bought it / Acho que ele acreditou) têm o mesmo valor semântico, embora haja uma perda do efeito cômico, uma vez que a expressão metafórica presente no texto-fonte realça a ideia de deboche na fala do personagem que, em stricto sensu seria "Acho que ele comprou". 
Tirinha 8
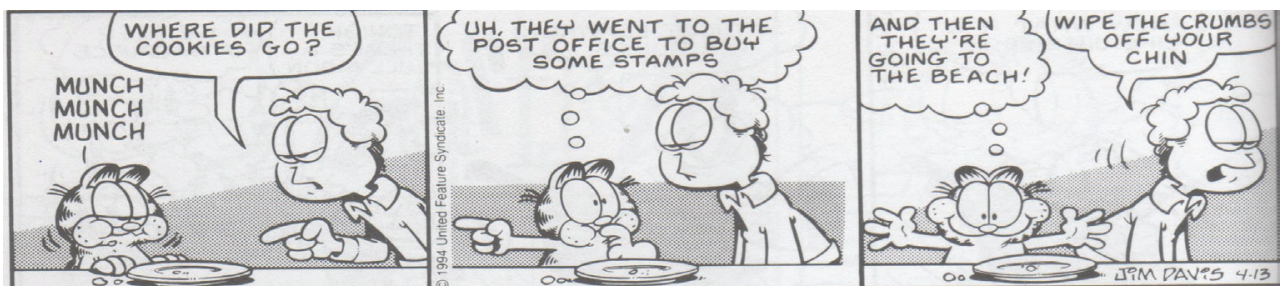

Fonte: DAVIS, Jim. Garfield dishes it out. Nova Iorque: Ballantine Books, 1995, não paginado.
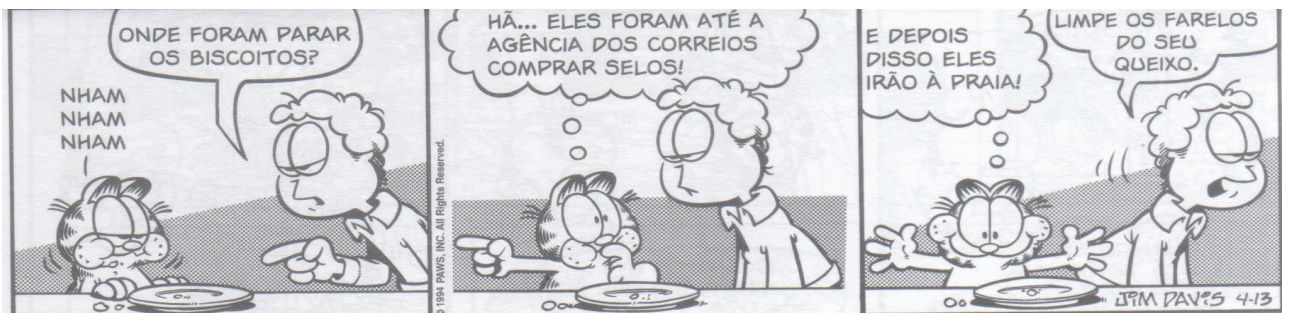

Fonte: DAVIS, Jim. Garfield está de dieta. Porto Alegre: L\&PM, 2013, p. 93.

Metáfora conceptual: ALIMENTO É PESSOA

Expressões metafóricas licenciadas na língua-fonte (em destaque):

a) Where did the cookies go?

Tradução para a língua-alvo: Onde foram parar os biscoitos?

b) Uh, they went to the post office to buy some stamps.

Tradução para língua-alvo: Hã...eles foram até a agência dos correios comprar selos!

c) And then they are going to the beach!

Tradução para a língua-alvo: E depois disso eles irão à praia!

Alternativas de tradução aplicadas em cada enunciado:

a) stricto sensu; b) stricto sensu; c) stricto sensu

Funcionalidade das traduções: As traduções são funcionais, tendo em vista não só a correspondência metafórica conceptual entre ambas as culturas envolvidas, como também o fato de que o efeito cômico se mantém. 
Tirinha 9

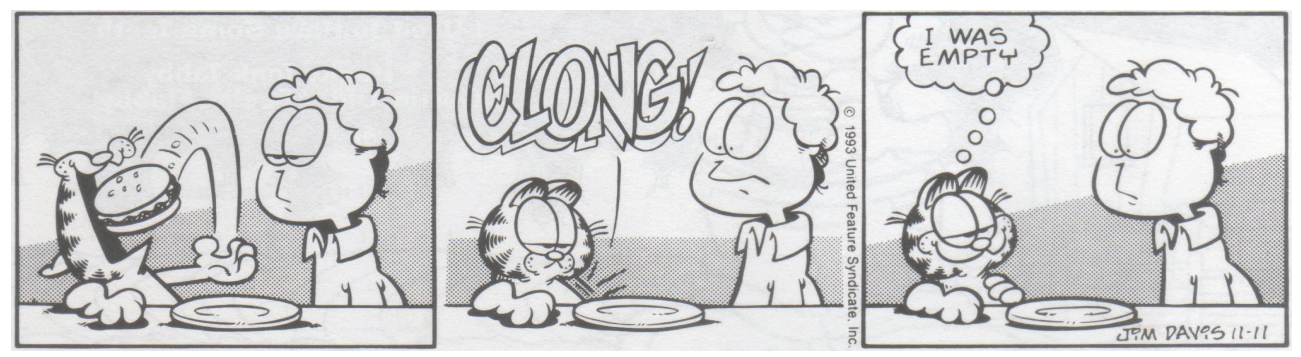

FONTE: DAVIS, Jim. Garfield dishes it out. Nova Iorque: Ballantine Books, 1995, não paginado.
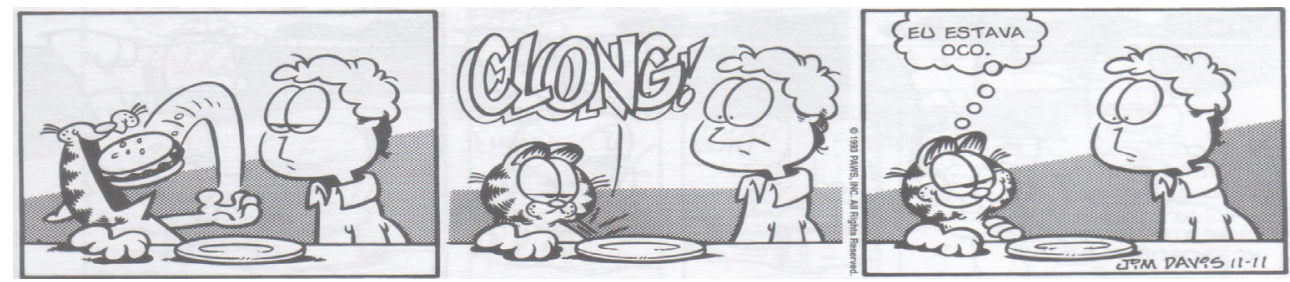

FONTE: DAVIS, Jim. Garfield está de dieta. Porto Alegre: L\&PM, 2013, p. 5.

Metáfora conceptual: CORPO É UM RECIPIENTE

Expressão metafórica licenciada (em destaque): I was empty.

Tradução para a língua-alvo: Eu estava oco.

Alternativa de tradução aplicada: stricto sensu

Funcionalidade da tradução: No contexto apresentado na tirinha, oco e vaz̧io (empty), apresentam-se como sinônimos. Assim, aqui tópico e veículo são traduzidos literalmente, o que configura a tradução como stricto sensu. A alternativa de tradução mostra-se funcional, tendo em vista que, em nossa cultura, a metáfora conceptual CORPO É UM RECIPIENTE é bastante comum, o que nos permite dizer, por exemplo: Estou me sentindo cheio (de comida); Estou oco (de fome); Ela é cheinha (gordinha), etc. 
Tirinha 10
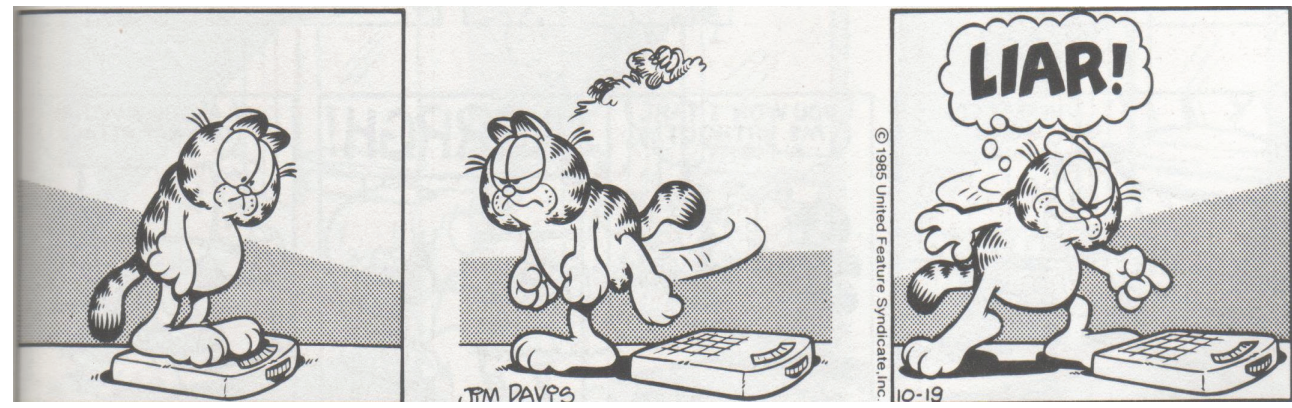

Fonte: DAVIS, Jim. Garfield food for thought. Nova Iorque: Ballantine Books, 1987, p. 45.
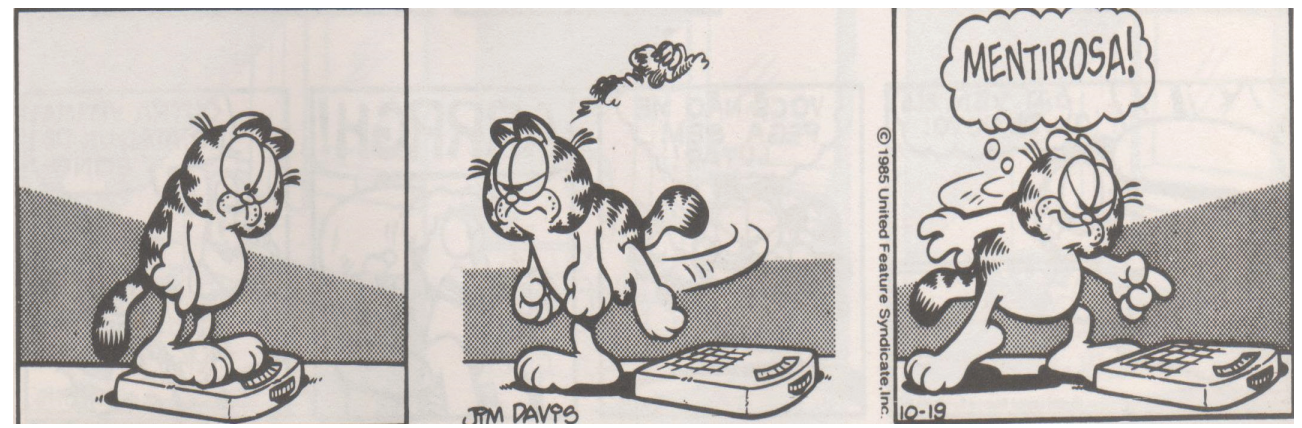

Fonte: DAVIS, Jim. Garfield em ação 11. Rio de Janeiro: Salamandra, 1989, não paginado.

Metáfora conceptual: OBJETO (BALANÇA) É PESSOA

Expressão metafórica licenciada (em destaque): Liar!

Tradução para a língua-alvo: Mentirosa!

Alternativa de tradução aplicada: stricto sensu

Funcionalidade da tradução: A metáfora conceptual OBJETOS SÃO PESSOAS é bastante comum tanto em língua inglesa, quanto em língua portuguesa. No caso específico das tirinhas apresentadas, temos uma comparação entre a balança e um ser humano, pois só uma pessoa pode mentir, essa é uma característica exclusivamente humana, que foi aplicada a um objeto. A tradução é funcional e mantém o efeito cômico, uma vez que há correspondência metafórica entre as culturas envolvidas. Quando chama a balança de mentirosa, Garfield mostra sua indignação com os números que aparecem no visor, culpando a balança pelo resultado. 


\section{Considerações finais}

A partir dar tiras cômicas selecionadas, foram estudadas as traduções de 13 expressões metafóricas. Analisando esse material, foi possível perceber que há uma maior incidência de traduções stricto sensu (8 ocorrências), em que tópico e veículo são traduzidos literalmente da língua-fonte para a língua-alvo.

A segunda possibilidade tradutória mais aplicada foi a paráfrase (5 ocorrências), que é caracterizada pela tradução da expressão metafórica encontrada na língua do original por uma palavra, expressão ou frase não metafórica na língua a que se destina a tradução.

Em relação à possibilidade tradutória de substituição, (quando uma expressão metafórica na língua-fonte é substituída por outra equivalente na língua-alvo), não foi encontrada nenhuma ocorrência dentre as traduções analisadas.

No total das traduções observadas, mais da metade são traduções literais (stricto sensu), assim conclui-se que isso pode indicar a existência de grande correspondência entre os sistemas conceptuais das culturas americana e brasileira. Por outro lado, também foi verificado um número significativo de traduções por paráfrase em tiras que traziam metáforas conceptuais correspondentes entre as línguas fonte e alvo (PELE É UMA ROUPA; AMOR É LOUCURA; MENTE É UM RECIPIENTE; QUALIDADE É UM OBJETO MENSURÁVEL; IDEIAS SÃO BENS DE CONSUMO). Isso pode indicar que, mesmo mediante tal correspondência, nem sempre a tradução literal das expressões metafóricas é a escolha tradutória utilizada, cabendo ao tradutor avaliar e adotar a opção mais adequada na transferência das expressões metafóricas de uma língua para a outra, considerando a funcionalidade da tradução no contexto linguístico-cultural para a qual o texto se destina.

\section{Referências bibliográficas}

ALDRIGUE, Natália de Sousa. A metáfora conceptual como recurso argumentativo em folderes turísticos. 2007. 78p. Dissertação apresentada para a obtenção do título de Mestre em Linguística. Universidade Federal da Paraíba, João Pessoa.

ALDRIGUE, Natália de Sousa; ESPÍNDOLA, Lucienne. Expressões linguísticas metafóricas como recurso argumentativo em folderes turísticos. Veredas Online, Juiz de Fora, v. 15, n. 2, p. 190-201, 2011.

Davis, Jim. Garfield dishes it out. Nova Iorque: Ballantine Books, 1995. 
1988.

Garfield em ação 10. Tradução de Lygia da Veiga Pereira. Rio de Janeiro: Salamandra, . Garfield em ação 11. Tradução de Lygia da Veiga Pereira. Rio de Janeiro: Salamandra, 1989. 1989.

Garfield em ação 13. Tradução de Lygia da Veiga Pereira. Rio de Janeiro: Salamandra, - Garfield está de dieta. Tradução da Intercontinental Press. Porto Alegre: L\&PM, 2005. . Garfield food for thought. Nova Iorque: Ballantine Books, 1987. . Garfield leva o bolo. Tradução de Laura R. B. Ribeiro. São Paulo: Cedibra, 1982. - Garfield na balança. Tradução de Laura Barretto. São Paulo: Cedibra, 1986. . Garfield out to lunch. Nova Iorque: Ballantine Books, 1986. - Garfield swallows his pride. Nova Iorque: Ballentine Books, 1987. . Garfield takes the cake. Nova Iorque: Ballantine Books, 1982. . Garfield tips the scales. Nova Iorque: Ballantine Books, 1984.

FARIAS, Cláudia V. V. N. A metáfora na leitura em língua estrangeira: efeitos de uma intervenção pedagógica. 2006. 151 p. Dissertação apresentada para a obtenção do grau de Mestre em Letras. Universidade Federal Fluminense, Niterói.

LAKOFF, George; JOHNSON, Mark. Metáforas da vida cotidiana. Tradução do Grupo GEIM. Campinas, SP: Mercado das Letras; São Paulo: EDUC, 2002.

KOGLIN, Arlene. A tradução de metáforas em tiras do Garfield. Scientia Traductionis. Florianópolis, $\mathrm{n}^{\mathrm{o}}$ 3, t. 8, p. 1-13, 2006.

- A tradução de metáforas geradoras de bumor na série televisiva Friends: um estudo de legendas. 2008. 99 f. Dissertação de Mestrado em Estudos da Tradução. Universidade Federal de Santa Catarina, Florianópolis.

; OLIVEIRA, S. M. Metáfora e humor: uma abordagem cognitiva. In: VIII Encontro do Círculo de Estudos Linguísticos do Sul, 2008, Porto Alegre. Anais do $8^{\circ}$ Encontro do CELSUL. Pelotas: EDUCAT, 2008. p. 1-11.

; SOUZA, A. C. Metáforas em tiras humorísticas: estratégias de tradução. In: MAGALHÃES, J. S; TRAVAGLIA, L. C. (Org.). Múltiplas perspectivas em Linguistica. Uberlândia: Edufu, 2008. V. 1, p. 480-488.

SARDINHA, Tony Beber. Metáfora. São Paulo: Parábola Editorial, 2007.

van den BROECK, R. The Limits of Translatability Exemplified by Metaphor Translation. Poetics Today, v. 2, n. 4, p. 73-87, 1981.

ZANOTTO, Mara Sophia. et. al. Apresentação à edição brasileira. In: LAKOFF, G.; JOHNSON, M. Metáforas da vida cotidiana. São Paulo: Educ, 2002. 